\title{
Expeditious $\alpha$-Hydroxylation of Ketones in Water Using Microwave Irradiation
}

\author{
Jong Chan Lec, ${ }^{\star}$ Eun Sang Yoo, and Jin Young Park \\ Department of Chemistry, Chung-Ang University, Seotl 156-756. Korea \\ Received Jily 21, 2004
}

Key Words : Aqueous, Hydroxylation, Hypervalent iodine. Ketones, Microwave

The $\alpha$-hydroxyketone moiety is commonly found in a wide varicty of naturally occurring biologically active substances.' This moiety is also served as a very useful intermediate in a number of important organic transformations. ${ }^{2}$ of the various synthetic approaches for the preparation of $\alpha$-hydroxyketones, the most frequently used methodologies are mainly based on the direct reaction of ketones with hypervalent iodine compounds under basic conditions in various organic solvents. Representative examples are the reaction of ketones with iodosobenzene in methanolic sodium hydroxide ${ }^{3}$ and the reaction with poly|4(diacetoxyiodo)styrene/ $\mathrm{NaOH}$ in methanol. ${ }^{+}$There are far less reports on the methods that dealt with the direet conversion of ketones to the $\alpha$-hydroxyketones under acidic conditions in the presence of hypervalent iodine compounds. These methods include the $\alpha$-hydroxylation of ketones with |bis(trilluoroacetoxy) |iodobenzene/trifluoroacetic acid in aqueous acetonitriles and reaction of ketones with polymersupported iodobenzene diacelate/trilluoroacetic acid in the solvent mixture of dichloromethane/acelonitrile." All of above mentioned methods have some degree of general applicability, but most of them are associated with at least one of the following drawbacks such as long reaction times. low yiclds, unavailability of the reagents, and tedious experimental procedures.

In these eco-conscious days, rescarches have been increasingly devoted to development of environmentally benign synthetic procedures. In this context, organic reactions in cheap and nontoxic aqueous reaction media have been attracting much attention. ${ }^{7}$ It would be highly desirable to be able to use of water to avoid any inllammable and toxic organic solvent in organic translormations.

Over the last decade, application of microwave irradiation technique in organic synthesis become popular due to its characteristic properties such as increased yiclds, higher selectivity, operational simplicity, and rapid reaction times. ${ }^{8}$ Hence development of eco-friendly new synthetic methods occurring in water under microwave irradiation conditions with nontoxic hypervalent iodine compounds would be of great utility. I Iowever, to our knowledge, synthetic method for the $\alpha$-hydroxylation of ketones under microwave irtadiation conditions has been unprecedented.

In connection with our ongoing interest on the utilization of microwave irradiation technique in developing new

Conespending Author. 'Tel: · 82-2-820-5202: 1:ax: + 82-2-825-4736: e-mail: jcleencau.ac.hr synthetic methods, we now report for the first time, an eflicient and envirommentally friendly method to reach $\alpha$ hydroxyketones in water under microwave imadiation avoiding use of any organic solvents. Direct treatment of ketones with iodobenzene diacelate and 2,4-dinitrobenzenesulfonic acid hydrate in water under microwave irradiation at $200 \mathrm{~W}$ for 2-3 min using CEM Discover monomode microwave reactor provided the corresponding $\alpha$-hydroxyketones.

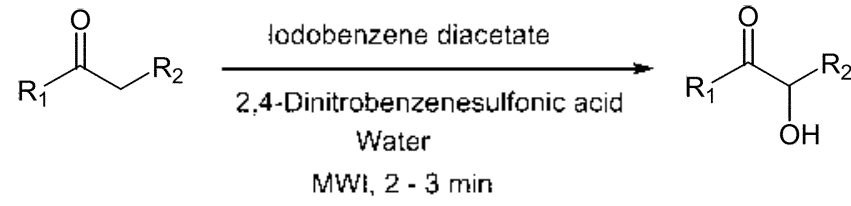

The $\alpha$-hydroxylation of various ketones proceeded effectively provided the corresponding $\alpha$-hydroxyketones in high yields as shown in the Table 1 . The cyclic kelones such as cyclopentanone and cyclohexanone also reacted smoothly to

Table I. Yields of $a$-hy droxy carbonyl compounds obtained under microwave irtadialion

\begin{tabular}{|c|c|c|c|}
\hline Entry & $\mathrm{R}_{\mathrm{I}}$ & $\mathrm{R}_{2}$ & Yicld $(\%)^{n}$ \\
\hline 1 & $\mathrm{C}_{3} \mathrm{ll}$ & II & 86 \\
\hline 2 & $4-(\mathrm{OMe}) \mathrm{C}_{0} \mathrm{H}_{4}$ & II & 85 \\
\hline 3 & $4-\left(\mathrm{NO}_{2}\right) \mathrm{C}_{6} \mathrm{l}_{4}$ & II & 67 \\
\hline 4 & $\mathrm{C}_{3} \mathrm{II}_{5}$ & $\mathrm{CH}_{3}$ & 84 \\
\hline 5 & $4-\left(\mathrm{Cl}_{3}\right) \mathrm{C}_{0} \mathrm{II}_{4}$ & $\mathrm{Cl}_{3}$ & 79 \\
\hline 6 & $4-(\mathrm{Br}) \mathrm{C}_{6} \mathrm{I}_{4}$ & $\mathrm{CH}_{3}$ & 67 \\
\hline 7 & $-1 \mathrm{C}$ & & 77 \\
\hline 8 & $-1 \mathrm{C}$ & & 65 \\
\hline 9 & & & 82 \\
\hline 10 & & & 88 \\
\hline 11 & & & 72 \\
\hline 12 & & & 66 \\
\hline
\end{tabular}

"Isolated yields. 
give the corresponding $\alpha$-hydroxyketones at the present conditions (entries 7-8). In most cases. the yields are superior or comparable to those obtained from the other direct conventional methods. ${ }^{56}$ It is presumed that the $\alpha$ hydrosylation occurred via nucleophilic substitution of the $\alpha$-phenyliodonium sulfonate intermediates by water molecules. An analogous mechanism has been reported for the substitution reaction of $\alpha$-pheny liodonio- $\beta$-dione intermediate by bromide ion to form $\alpha$-bromo-1.3-diones. The $\alpha$ hydroxylation of arylmethylene ketones also aclieved in high yields (entries 4-6). In cases of reported conventional methods utilizing hypervalent iodine compounds, the yields of $\alpha$-hydroxy lation of ary lmethylene ketones were generally poor. For examples, the $\alpha$-hydroxylation of propiophenone and $p$-bromopropiophenone with [bis(trifluoroacetosy)]iodobenzene/trifluoroacetic acid in $\mathrm{CH}_{3} \mathrm{CN} / \mathrm{H}_{2} \mathrm{O}$ gave the corresponding $\alpha$-hydroxyketones in $36 \%$ and $21 \%$ yields respectively in conventional conditions. ${ }^{5}$ This funding is noteworthy as it indicated the much higher formation of enol tautomer under the microwave irradiation conditions in comparison with that of conventional reaction conditions.

Monohydroxylation of cyclic $\beta$-keto esters have attracted much attention because of their presence in biologically inportant natural products. ${ }^{11}$ Very recently. $\alpha$-hydroxylation of cyclic $\beta$-keto esters have been achieved utilizing oxidation with reagent combination of molecular oxygen/cobalt(II) chloride in $\mathrm{CH}_{3} \mathrm{CN} / i$ - $\mathrm{PrOH}^{1]}$ and reaction with molecular oxygen/ cerium(III) chloride in $i-\mathrm{PrOH}^{12}$ Thus, we next exanined the utility of the present reaction conditions for $\alpha$ hydroxylation of cyclic $\beta$-keto esters. As shown in Table 1 at entries 11 and 12. oxidation of cyclic $\beta$-keto esters proceeded very well in $3 \mathrm{~min}$ to give corresponding $\alpha$-hydroxy$\beta$-keto esters with high yields. Therefore, this new protocol can be also served as a valuable alternative for the existing methods in $\alpha$-hydroxylation at the tertiary position to cyclic $\alpha$-keto esters. General experimental procedure is as follows: A misture of ketone (1.0 nimol). iodobenzene diacetate (0.485 g. $1.5 \mathrm{mmol}$ ) and 2,4-dinitrobenzenesulfonic acid hydrate $(1.120 \mathrm{~g} .4 .5 \mathrm{mmol})$ in distilled water $(20 \mathrm{~mL})$ was placed into a quartz cylindrical flask in a CEM Discover ${ }^{\sqrt{2}}$ monomode microwave reactor under a reflux condenser and irradiated for $2.3 \mathrm{~min}(200 \mathrm{~W})$ at $80^{\circ} \mathrm{C}$. After completion of the reaction. the mixture was extracted with dichloromethane $(3 \times 25 \mathrm{~mL})$ and washed with water $(20 \mathrm{~mL})$. The collected organic fractions were dried on $\mathrm{MgSO}_{4}$, and the solvent evaporated under vacuum. The residue was cluromatographed on silica gel using a mixture of ethyl acetate and hexane $(1: 2)$ as eluent to give a purified $\alpha$ hydroxyketone.

In summary, a facile, highly efficient, and envirommentally benign protocol has been newly developed for the preparation of $\alpha$-hydroxyketones and cyclic $\alpha$-lyydrosy- $\beta$ keto esters by use of microwave irradiation in water.

Acknowledgment. We thank the KOSEF (R-01-1999$000-00036-0$ ) for financial support of this work.

\section{References and Notes}

1. Raduchel. B. Symthesis 1980. 292.

2. (a) Trost. B. M.: Terrell. L. R. J. Am. Chem. Soc. 2003. 125. 338. (b) Yoshikawa. N.: Suzuki. T.: Shibasaki. M. J. Org. Chent. 2002. 67. 2556. (c) Hasiyama. T.: Morikawa. K.: Sharpless. K. B. J. Org. Chent 1992, 57, 5067.

3. Moriarty, R. M.; Hu, H. Gupta. S. C. Tetahedron Lett. 1981. 22. 1283.

4. Togo. H.: Abe. S.: Nogami. G.: Yokoyama. M. Bull. Chem So. Jpn. 1999. 72.2351 .

5. Moriarty. R. M.: Berglund. B. A.: Penmasta. R. Tetrahedhon Lent 1992. 33, 6065 .

6. Ley, S. V: Thomas. A. W.: Finch, H. J. Chem Soc, Perkin Trans. 1 1999, 669

7. Li. C.-J:- Chan1. T. H. Organic Reactions in Aqueous Media: Tohn Wiley \& Sons: New York. 1997: pp 64-114.

8. Microwaves in Organic Smthesis. Loupy. A.. Ed.: Wiley-VCH Weinheim, 2002.

9. Coats. S. J.: Wasserman, H. H. Tetrahedron Lett. $1995.36,7735$.

10. (a) Olack. G.: Morrison. H. J. Org. Chem. 1991. 56, 4969. (b) Crout. D. H. G.: Lee. E. R.: Pearson. D. P. T. J. Chem Soc. Chem Contmi 1990.331.

11. Baucherel. X.: Levoirier. E.: Uziel. J.: Tuge. S. Tetrahedron Lett. 2000. $+1,1385$.

12. Christoffers. J.: Werner. T.: Unger. S.; Frey. W. Ew d. Ong Chem. 2003. 425 